Research note

\title{
Valuation Mishaps and the Choreography of Repair
}

\author{
Claes-Fredrik Helgesson and Steve Woolgar
}

\begin{abstract}
This research note proposes that it is instructive to ask what happens when evaluative practices go wrong. It shows how a close study of mistakes and mishaps in evaluation-both in the process of their disclosure and subsequent management-provides important insights into ways in which evaluation practices contribute to performing and sustaining the relations of accountability involved. The note examines two cases: 1 ) the mistaken award of the 2017 Oscar for Best Picture and 2) the incident in November 2016 when Thomson Reuters notified a large number of scholars that they had been awarded the distinction of being a "Highly Cited Researcher" in their field, only a few hours later to retract these awards. Studying such instances provides insights into what is at stake for participants, the choreography of performing and revealing evaluations, the ways in which different evaluation practices fold together, and the accountability structures which support valuation practices.
\end{abstract}

Key words: mistakes; mishaps; repair; evaluation practice; accountability relations; choreography

\section{Evaluation Mishaps in the Spotlight}

What happens when an evaluation mishap occurs in public display? What can we learn about valuation practices if we examine such mishaps? How are such mishaps publicly repaired? The mistaken announcement of "La La Land" as winner of Best Motion Picture at

Claes-Fredrik Helgesson, Department of Thematic Studies-Technology and Social Change, Linköping University, Sweden, claes-fredrik.helgesson@liu.se

Steve Woolgar, Department of Thematic Studies-Technology and Social Change, Linköping University, Sweden, steve.woolgar@liu.se

(C) 2018 Authors

LiU Electronic Press, DOI 10.3384/VS. 2001-5992.1852145

http://valuationstudies.liu.se 


\section{Valuation Studies}

the Academy award ceremony in 2017 drew our attention to these questions. It has previously been noted how valuations sometimes are devoured as a public spectacle such as in televised shows like the Antiques Roadshow, American Idol and Dragons' Den (Muniesa and Helgesson 2013). More broadly, prizes and awards are regularly presented at ceremonies, prestigious appointments are made public through press releases and so on. The iconic academic award of the Nobel Prize is, for instance, associated both with the intricate procedures for determining the winners and with the ornate award ceremony (Woolgar 1980). Such public performances can be seen as providing the unequivocal sanction of sometimes prolonged and convoluted practices of assessment. It is precisely the stakes attached to such presumed public unequivocal sanctions that make the occurences of mishaps interesting. The 2017 Oscar mishap piqued our curiosity precisely because it exemplified the public unmaking of a definite announcement and the public making of a new, equally definite, announcement.

Valuation practices have proliferated in recent decades and are now a pervasive feature of widespread activities and situations. Their public performances have similarly come to occupy most public spaces for announcing and solidifying their outcomes. Although various valuation practices are increasingly examined, not least within the remit of this journal, there is to our knowledge little attention given to those occasions when the public performance of a valuation is recognised as generating a mistaken outcome. Our intention with this research note is to initiate an exploration of the topic of public mishaps and mistakes in the public performance of evaluation. We will specifically examine two recent public mishaps in evaluation. First, the above mentioned announcement of "La La Land" as winner of Best Motion Picture at the Oscars award ceremony in 2017. Second, the announcement and subsequent retraction of a number of "Highly Cited Researcher" (HCR) distinctions by Thomson Reuters in November 2016. Our intent is to use this examination to highlight features of valuation practices which are normally taken for granted.

Our initial intuition is that many mechanisms of assessment tend to be well orchestrated; that is, many routines and networks for arriving at a conclusion are well established. After all, high stakes often attach to singling out what or who is valuable and worthy among many contending alternatives. Yet, apart from critically assessing these valuation practices, and contributing to debates about their deleterious effects, an additional task is to understand the nature of evaluation when things go wrong in public. Our exploration of public mishaps and their repair is aimed at furthering our understanding about valuation practices. Our interest in these two cases is directed towards what they might tell us about two interrelated key features of valuation practices. The first feature is how the actors involved attach 
particular significance and importance to the evaluation: what for them are the matters at stake. The second feature concerns the staging and public performance of valuations, and the subsequent public repair of the mishap. These two features are interrelated not least in how different valuation practices might be folded together and by the accountability structures that support valuations. We use our examination of these features to sketch a more general scheme for analysing public performances of valuations and their mishaps.

\section{"This is not a joke, I'm afraid they read the wrong thing"}

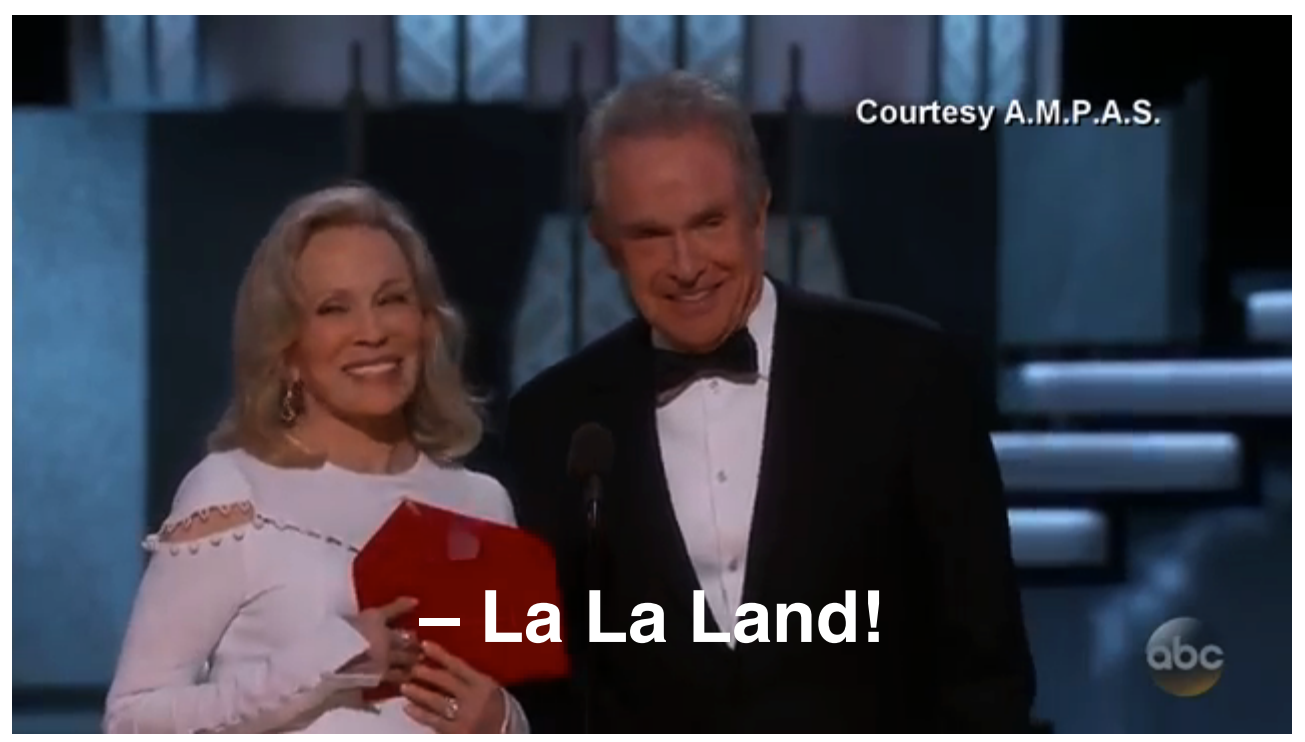

Figure 1 Faye Dunaway and Warren Beatty announcing the award for Best Picture, 26 February 2017 (subtitle added)

Presenters Faye Dunaway and Warren Beatty (Figure 1) are charged with the announcement of the award for Best Picture, the culmination of an evening of announcements of awards in different categories across the movie industry. Beatty opens the envelope and, after (what we retrospectively notice as) some hesitation (indexed with "You're impossible!" from Dunaway), hands over the note and the envelope to Dunaway who announces the winner: "La La Land." Amid substantial applause and much hugging and hand shaking, a large team of some twenty actors, producers, directors, technical contributors and so on then take to the stage, joining Beatty and Dunaway. While they move to the stage, the voice over on the TV coverage narrates that La La Land had the tied record in Oscar history for most Oscar nominations (14), and recounts the seven Oscars it had received-production design, cinematography, etc.- - ending with the just announced award for Best Picture. From a position behind and above the scene, the TV 


\section{Valuation Studies}

camera pans up and down the full length of the packed audience, who delightedly exclaim and applaud the awardees facing them at the front (Figure 2a). The Oscar is handed over and there then ensues a sequence of acceptance speeches by members of the team (Figure $2 b$ ).
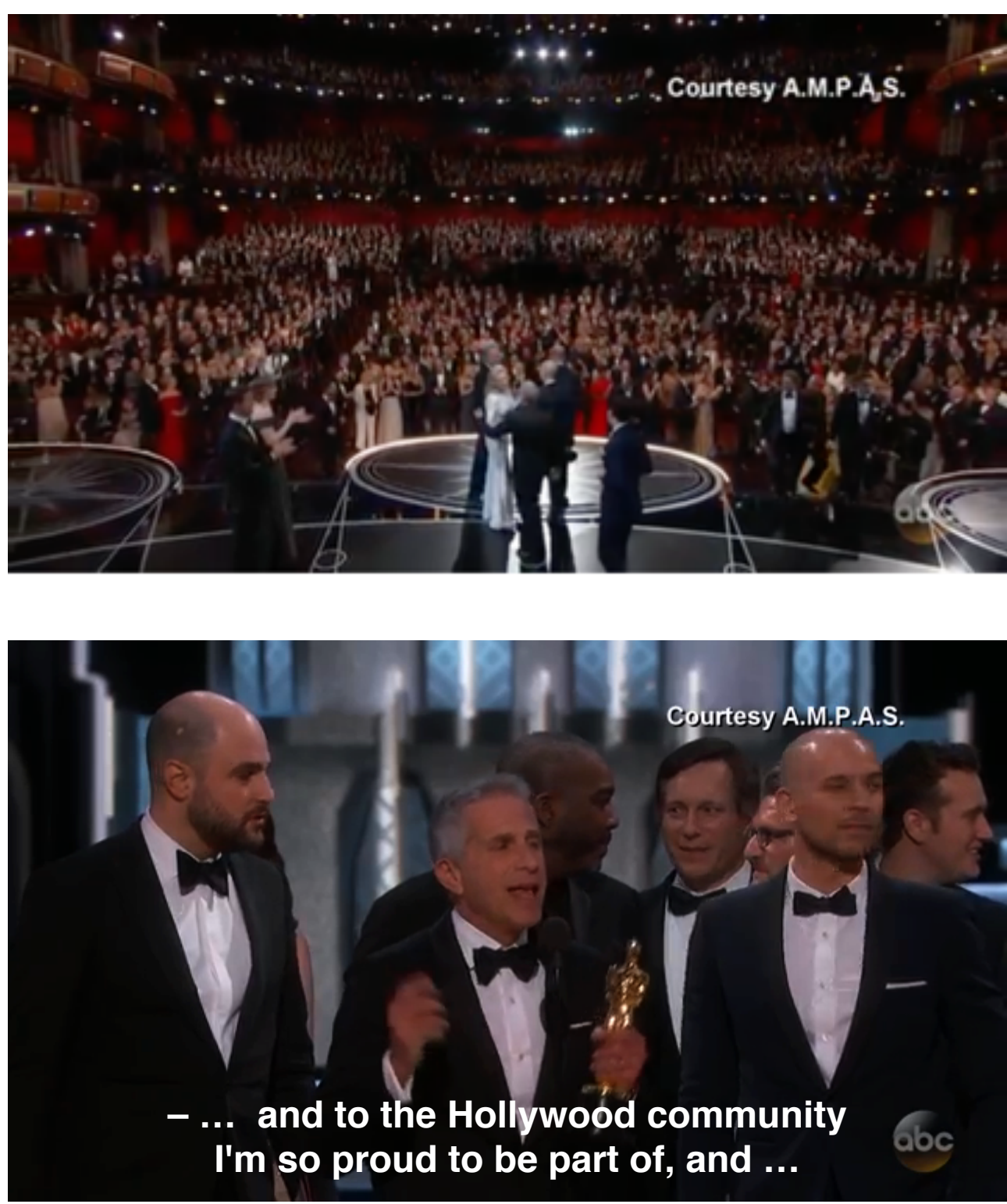

Figures $\mathbf{2} \mathbf{a}, \mathbf{2} \mathbf{b} \quad$ The audience witnessing and applauding the awardees arriving on the stage ( $2 \mathrm{a}$ top). The subsequent thank you speech by La La Land producer Marc Platt (2b bottom). Platt is flanked by fellow producers Jordan Horowitz to the left and Fred Berger to the right.

From the opening of the envelope, some 2 mins 30 secs pass before the award is announced as a mistake. Our retrospective viewing of this period is a form of dramatic irony: because we now know what the actors do not, we can now notice things having gone wrong. For 
example, we notice the gradual appearance on stage, in among the assembled La La Land throng, of "back stage" personnel: a man with a clipboard, another with headphones. The direction and speed of their presence and movements seem oddly orthogonal to those of the celebrant La La Landers: they do not face the audience, they are not laughing and smiling, they are not talking to one another. A sequence of thank you speeches gets underway. Yet word seems gradually to spread among those on stage that something is wrong. Until a producer of La La Land, Jordan Horowitz, clutching his ("his") Oscar, steps up to the microphone and declares (at 2.43) "Wait. Guys. No. There's a mistake. Moonlight. You guys won Best Picture ... this is not a joke." Followed by Marc Platt, outside the frame, repeating "this is not a joke" followed by "I'm afraid they read the wrong thing." Close reviewing of the video reveals that this is immediately preceded (at 2.41) by Horowitz's fellow producer Fred Berger, in mid-thank you speech, briefly saying into the microphone "We lost by the way but you know (huh huh)" (shrugs shoulders).

We can understand the drama of the revelation as a reflection of the extent of investment in the network which constitutes the evaluation. Elsewhere we have described the networks which constitute the persona of a celebrity such as Jimmy Savile, and how the degree of investment in these networks accounts for the extent of drama and consternation when the same persona/network is radically disrupted (Woolgar, forthcoming). In the current case we mean investment in both, on the one hand, the procedures for soliciting nominations for awards, assessment; and on the other, investment in the staging, resources and enactment of roles and identities for the announcement of the award. As we discuss below, accomplishing this distinction between the evaluation itself and its (mere) subsequent announcement is crucial to the repair mechanism which ensues. In articulating the "mistake" the announcement is enacted as a mere epiphenomenon to the machinery of evaluation.

Certainly, reactions to the revelation of the mistake were dramatic, perhaps also indicating the perception of the high stakes involved. The incident is described as "the most infamous moment in Academy Awards history." The Academy Awards show producer Michael de Luca said "It was like the Hindenburg report. [A reference to the 1937 air ship disaster which stunned the nation.] I literally heard, 'Oh my God! He got the wrong envelope!' And then it was slow motion. You perceive things slowly as the adrenaline rises and the cortisol floods your system."

A first key aspect of this episode is the interlinking of repair and post mortem. How to make good the mistake that was made, and whom/what to blame for the mishap?

As the event unfolds, and in its immediate aftermath, we see accountability for the mistake shift from Warren Beatty and Faye 


\section{Valuation Studies}

Dunaway (the voice of Marc Platt at 2.53 saying "I'm afraid they read the wrong thing"), to Warren Beatty alone (at 3.52 Jimmy Kimmel, the host of the evening, says to Beatty "Warren, what did you do?!"). Subsequently blame shifts to the Academy management in general, to PricewaterhouseCoopers ( $\mathrm{PwC}$ ) ("the Academy's accounting firm for 83 years"), and finally to one individual, Brian Cullinan, one of PwC's managing partners. The latter's "human error" was later cited as the reason for the mix-up, and he is vilified for his behaviour:

A Harley-riding Malibu resident and self-proclaimed Damon look-alike (he has proudly announced that on Facebook), Cullinan is being blamed for allowing himself to be distracted by the celebrities who surrounded him. He tweeted a photo of [Emma] Stone minutes before the mix-up despite reportedly being asked not to do so. [Emma Stone had just won Best Actress for her role in La La Land.]

The stage is set for the articulation of "human error" at an early point in the proceedings. At 3.22 in the video clip the host Jimmy Kimmel comes to the front of the on-stage assembly-in the background one sees the cast of winners and (now revealed) losers exchanging placesand says "This is very unfortunate what happened. Personally I blame Steve Harvey for this." The comment comes across as a jocular reference to a previous, notoriously high profile error when, at the culmination of the Miss Universe 2015 pageant, the host mistakenly announced the wrong winner of that title. Of course, the comment works more as a joke than a serious attempt to explain what is happening, as a reflection on the embarassment, doubt and uncertainty which characterises the unfolding situation. Interestingly though, the joke is framed in terms of individual rather than, say, organisational failure. It can be understood as saying Steve Harvey messed up: an individual was to blame: human error is how we can understand what just happened here.

The importance of the repair work, as mentioned, is in distinguishing between the actual state of affairs (the correct evaluation) and its merely mistaken articulation. It is worked to substantiate the claim that although the machinery of evaluation misfired this time, it did so only in the final expression of its result. There is essentially nothing wrong with the machine: instead some kind of peripheral "human error" is at fault.

A second key aspect is in the choreography of revelation and repair of the mistake. We note that two casts of witnesses to the event are quite literally substituted one for the other. The entourage associated with La La Land gets to take back stage (and some of them seem to start to leave the stage) as they are replaced by the entourage associated with Moonlight. As mentioned already, the choreography involves the switch from smiling faces towards the camera and giving acceptance speeches, to the inclusion of back stage staff, to surprised exchanges between those on stage, to the denouement and declaration of a mistake. 
A particular material contributor to the choreography of the mistake is the envelope and the card announcing the winner. As part of the repair sequence the material entity (the envelope and the card within) is made to move around between actors as part of doing attribution and reassignment of accountability. It is subsequently decided that Warren Beatty had been given the wrong card. This (retrospectively) explains the pauses and other interactions between Beatty and Dunaway leading up to the erroneous announcement. Beatty was expecting to see a card stating the winner of the Best Picture but instead pulls out card stating that Emma Stone was winner of Best Actress award for her role in La La Land. The interaction that was previously readable as Beatty either dithering, perhaps incompetent or playing for time for dramatic effect (Faye Dunaway at $0.16)$ is now readable as incomprehension and hesitation about what to say. He passes the card to Dunaway who reads out the title of the film she sees on the card: La La Land.

At 2.57 Jordan Horowitz repeats "This is not a joke" and says "Moonlight has won Best Picture." Beside him Warren Beatty, holding another red envelope, opens it and pulls out the card within. It looks like Beatty is trying to get to the microphone to say something. If this is about "human error" Beatty needs to get into position to absolve himself of blame. But Horowitz takes the card from Beatty and says again: "Moonlight. Best Picture." He holds the card up to the camera. The camera stays in close up on the card for some 7 seconds (see Figure 3). The audience can now see the "correct" award as evidenced by the writing on the card. At 4.12 Beatty gets his say. He repeats a version of the now revealed sequence of events, again holding up the (correct) card to audience and camera: made to work as incontrovertible evidence of the correct state of affairs.

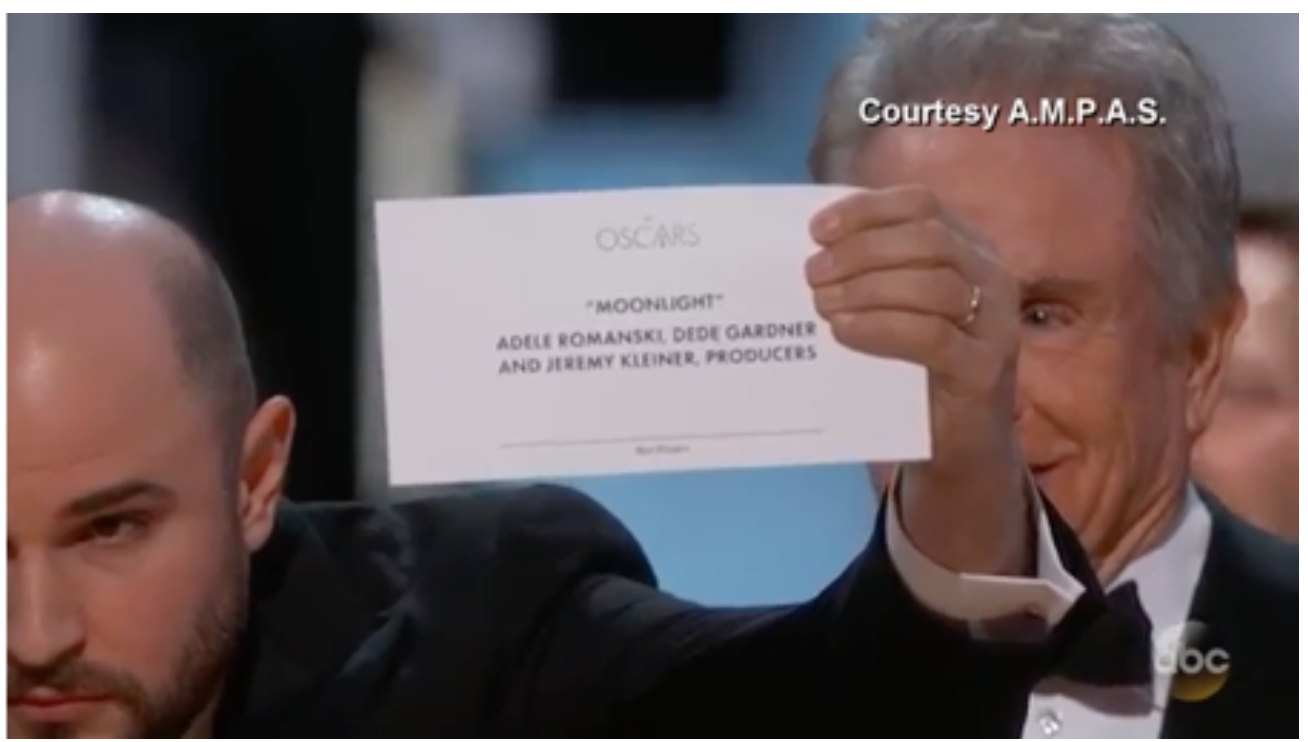

Figure 3 La La Land producer Jordan Horowitz presents the correct card. Warren Beatty, one of the two assigned presenters of the award, is directly behind Horowitz's hand holding the card. 


\section{Valuation Studies}

The receipt of an Oscar is not merely the final end mark of evaluation. The evaluation itself has immense prospective value. The film industry puts considerable effort into using these evaluations for future marketing. Thus for example subsequent films are advertised as "by the Oscar winning Director of ..." or "featuring Academy Award nominee ... ." So the award has a permanence which entails future value for other yet to be evaluated activities and products.

The permanence and prospective value of the award can thus be understood in terms of its folding potential (Deleuze, 1993). The value of the Oscar is prospectively transposed from one context (the award ceremony) to many others for different purposes. Folding the evaluation brings together disparate elements in a consequential manner.

Recognition of the significance of the folding of the award is evident in participants' public management of the misappropriation of prospective value. The (actual) losers' reactions can be read as displays of graciousness in the face of just having the award snatched from them. At 3.34 Horowitz, holding the Oscar, says "I'm going to be really proud to hand this to my friends at Moonlight" Amid renewed applause from the audience Jimmy Kimmel replies "That's nice of you, that's very nice." Goodwill is demonstrated. Unpleasantness is avoided. It is a "nice" gesture because we all appreciate the nature and extent of the folding opportunities which Horowitz is giving up. Subsequently Horowitz, now labelled as the "unlikely hero" of the event, stated:

I wanted to make sure that the right thing was done, because, you know, at that point it was not about me. It was about making sure that Moonlight got the recognition it really deserves.

So we see that the revelation and the subsequent repair of the mistake at the Academy Awards shows something of the structure in place which makes evaluation possible in the first place. To what extent can we take this as a typical choreography of evaluation? What is the nature of revelatory networks in evaluation? To what extent does this analysis apply to other instances of mistaken evaluation?

\section{Performing a valuation and the choreography of repair}

The transition between the "winning" "La La Land" to the winning "Moonlight" tells us much about the repair processes involved in public displays of valuation. The whole episode takes place in a high stakes setting celebrating achievements in film and in front of an illustrious live audience, a huge television audience and massive social media interest in Twitter and Facebook. Central aspects of the (original) announcement include a document, two witnesses, a huge audience and the unequivocal announcement. This is followed by the 
public appearance of recipients, to be displayed and to acknowledge their receipt of the reward. These are all central and easily recognised elements of the staging and public performance of a valuation.

What happens next are steps which we suggest look like a choreography of public valuation repair. Taking inspiration from Charis Cussins's (1996) notion of 'ontological choreography' we would take this choreography of public valuation repair as denoting the coordinated action of many diverse actors in the service of maintaining the integrity of the valuation practice in question.

The choreography of repair is instigated by a moment of commotion, uncertainty and lack of clarity as to what is actually going on. Actors, such as men with headsets appear, and the performances of thank-you speeches are gradually derailed. Then out of this moment of chaos, order resurfaces. This order highly resembles the first one prior to the commotion and involves a document (albeit new), witnesses, a huge audience, a new unequivocal announcement. This is followed by the appearance of the "real" recipients. Simultaneously, the previous recipients take on a new role as witnessing the (new) unequivocal announcement and certifying its authenticity. It is furthermore noteworthy that the live audience, having actively confirmed $\mathrm{La} \mathrm{La}$ Land as the winner with clapping and cheers, then shift and just as intensively confirm Moonlight as the winner. Why did they do that? A fictional interrogation of an imagined audience could provide some clues.

Steve Woolgar [SW]: How come you applauded and cheered the announcement of Moonlight as the winner in much the same way as you had done just before when La La Land had been announced as the winner?

The audience [TA]: It is all really simple: Moonlight was the winner! You have to acknowledge the winner when it is announced.

C-F Helgesson [CF]: Yes, but what about your applause and cheering for La La Land just minutes before?

TA: Well, that was when we thought La La Land was the winner. It is both appropriate and imperative that we confirm and acknowledge a winner when it is announced. At that time, none of us knew about the mistake. We heard later that it was something to do with misplaced envelopes and an auditor?

SW: What if it had turned out otherwise? What if the announcement of Moonlight as winner was the result of a second mistake? Would you have clapped and cheered yet again for the then announced winner?

TA: Well that's just silly! Moonlight was the winner, so of course we cheer and confirm the actual winner. It is stupid to speculate that this extraordinary eventuality might be just the first of its kind. 


\section{Valuation Studies}

CF: But how can you be so sure that this was just a one-off? Are you saying that when a mistake has been identified and corrected, the show just needs to go on? That there is no anxiety about whether or not any subsequent announcement is flawed?

TA: Well we don't know. That just sounds to us like fancy reasoning. As an audience we have to cheer and applaud the actual winner. That is what we do. This is not only about celebrating the winner, but about celebrating the very idea of the award. And, indeed, about celebrating the idea of audience. If you undermine the whole idea of the certainty of the award, what does that do to us as an audience? Our identity as audience depends on the award. After all, it was just a mistake!

A crucial part of the choreography of repair is the identification of the cause of the mistake. This is moreover done in a way that enacts a clear distinction between the evaluation machinery and the staging of the announcement of its outcome. Several attributions of "blame" are tested, but they all honour this distinction and attribute accountability for the mistake in the announcement. This works as an attempt, in the immediate setting, to preserve the integrity of the valuation and to reassert the significance of the assessment and the worthiness of the "true" recipients.

Much more repair work associated with the mistaken award continued well beyond the stage of the Oscar ceremony. A series of investigations, recriminations, public comment, questions of blame and dismissal followed the ceremony. These are beyond the scope of the present discussion: our purpose here is to highlight the choreography involved in attempts at repair specific to the particular moment and immediate setting of the announcement.

\section{"This was sent in error."-The Highly Cited Researcher Award 2016}

Each year Clarivate Analytics announces the publication of their annual list of HCRs. The list "is a citation analysis identifying scientists-as determined by their fellow researchers-whose research has had significant global impact within their respective fields of study.” In 2016 the list contained more than 3,000 researchers in 21 fields in the sciences and social sciences based on papers published during an 11-year period up until December 2014. As is usual, the announcement of the list includes a triumphal declaration of the prestige of the award by an authoritative figure in the organisation:

It is precisely this type of peer recognition, in the form of citations given and rooted in the collective and objective opinions of scientific field experts that makes achieving highly cited researcher status meaningful," said Jessica Turner, global head of government and academia at Clarivate Analytics. "We are proud that our list of Highly Cited Researchers has earned global respect among the 
academic and scientific community and has the potential to present new opportunities for career advancement, recruitment and institutional enrolment.

Universities employing researchers on the list had apparently been informed in advance, and issued press releases on the same day. For example, the National University of Singapore noted in their press release on 16 November that they had 11 scientists and engineers on the list and that it was the third year in a row in which NUS had the highest number of highly cited employees among all research institutes in Singapore.

On Friday afternoon of 18 November, one of us (Helgesson) was delighted to be informed by email from Thomson Reuters/Clarivate that he had been awarded the distinction of HCR. Helgesson was selected for this illustrious honour "because your work has been identified as being among the most valuable and significant in the field." The email further stated that very few earn this distinction and that the process of identifying him as a recipient had involved something called "Essential Science Indicators" and a ranking of the top 1 per cent most cited works for the given subject field.

The award included a downloadable badge which, it was suggested, could be displayed on his personal website, LinkedIn profile and email signature. The email provided a link for requesting a physical personalised letter and certificate for display. Finally, the email suggested that he should join the conversation on social media about this award using the hash tag \#HighlyCited. The email ended on a warming personal note from Vin Caraher, the CEO of Clarivate Analytics.

I applaud your contributions to the advancement of scientific discovery and innovation and wish you continued success.

What can be awarded, can as easily be taken away. Three hours and 45 minutes later Helgesson received a second mail from Thomson Reuters. This time it was not addressed to "Helgesson" personally, but to "Dear Researcher" and signed by the more anonymous "Clarivate Analytics." The gist of this second email was that the previous mail had been sent in error. Here is the full email:

Dear Researcher,

We recently sent you an email about being named a Highly Cited Researcher. This was sent in error. Please accept our sincere apologies.

We've identified the error in our system that caused this and were able to resolve it quickly, ensuring it won't be repeated. 


\section{Valuation Studies}

Highly Cited Researchers derive from papers that are defined as those in the top $1 \%$ by citations for their field and publication year in the Web of Science. As leaders in the field of bibliometrics we appreciate the effort required to reach this achievement and celebrate those who have done so this year.

Sincerely,

Clarivate Analytics

A quick search online indicated that he was not alone in having both received and lost this award within a few hours. The suggested hash tag \#highlycited was repurposed for discussing the retracted awards. Helgesson was among several who posted comments and offered modified badges to signal the mishap (see Figures 4 and 5).

\section{Daniel Torrico B Gdanitobaz + 19 Nov 2016}

I also received the award as \#Highlycited author and later received the apologies. What happened with Gwebofsciencel \#confused
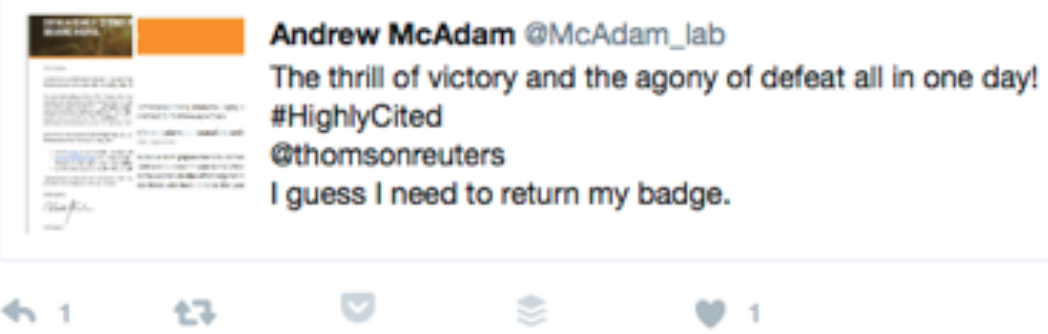

Figure 4 Excerpt from Twitter 19 November, the day after the mishap had been communicated
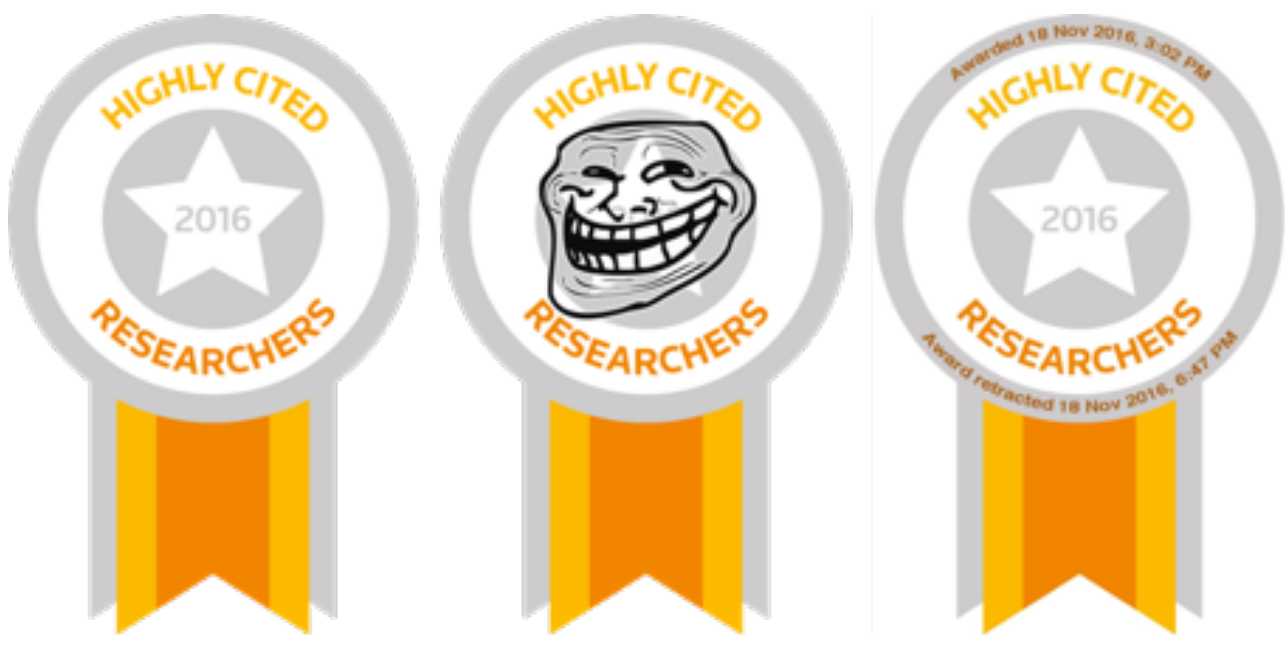

Figure 5 The original Highly Cited Award badge offered for download (left) and badges modified by Çetin Kocaefe (@cetinkocaefe, centre) and Helgesson (@cfhelgesson, right). 
The website Retraction Watch published a piece on the HCR mishap on the following Monday, the 21 November. The commentaries on this post were charged with emotion, as were several of the tweets following the mishap. At least one contributor threatened to sue Thomson Reuters. Some information communicated by Clarivate was also included in the Retraction Watch post where the company further discussed the nature of the mistake:

The error occurred internally with our email system. It was corrected quickly and we emailed apologies to those who received the incorrect email.

We take HCRs very seriously and since correcting this error, we are confident it won't be repeated.

Note here how the source of the mishap is located in the email system. The error is thus positioned as rather remote from the system and procedures used for actually identifying HCRs. These procedures are outlined on a page dedicated to describing the procedure:

...A ranking of author names in each ESI category by number of Highly Cited Papers produced during 2004-2014 determined the identification and selection of our new list of highly cited researchers. We used algorithmic analysis to help distinguish between individuals with the same name or name form (surname and initials). In instances where any ambiguity remained, manual inspection was needed. This entailed searching for papers by author surname and one or multiple initials, ordering them chronologically, visually inspecting each (noting journal of publication, research topic or theme, institutional addresses, co-authorships, and other attributes), and deciding which ones could be attributed to a specific individual. As noted in the FAQ [frequently asked questions] section, we examined original papers, if necessary, as well as the websites of researchers themselves and their curricula vitae. This was often required if a researcher changed institutional affiliations several times during the period surveyed ... (Excerpt of entry under Methodology).

\section{Another moment of commotion and a choreography of repair}

HCR recognition is not as front and centre in academic distinctions as is the Academy Awards in the motion picture industry. There is no glamorous televised celebration for HCR. Yet, it is directly associated with a dominant metric for assessing academic contributions, the citation, and the dominant enterprise making a business out of manufacturing such metrics. The above mishap did thus take place in a setting with significant stakes attached, where the distinction is not only linked to the status of scholars but to the ranking of universities and the myriad of ways that these can be translated into future funds. In short, HCR is intricately entwined with a number of consequential evaluation practices within academia. 


\section{Valuation Studies}

The first revelation of the assessment followed a script with several resemblances of the Oscar's announcement. We have the unequivocal announcement, the documents (press release and personalised letters) and an audience. As regards the audience, it is worth noting how the recipients were encouraged to conjure a wider audience to the whole affair with the use of badges, printed diploma, the social media hash tag and so on. Recipients are in effect encouraged to initiate their own folding of value. The audience confirming the distinction is in one manner to be assembled after the fact to confirm and witness that the distinction indeed has been awarded. Several tweets and university press releases indicate that this is also what happened.

Then there was the mishap. We do not have any insight into the instigation of the moment of commotion, but something must have warranted Clarivate to retract a presumably large number of recently minted HCRs via a second email. The cause of the mishap is quickly presented as being caused by an error in the email system. By implication, this is quite remote from the systems gathering and the processing of citation data that lay the foundation for identifying HCR. The erroneously awarded researchers transmute into a part of the audience. Aside of their complaints and ironic remarks, they also take part in being and widening the audience for the HCR distinction. At the same time "real" recipients continue to announce their distinction and thank their colleagues. Again, the assemblage was rather smoothly reordered to repair the mishap and conserve the integrity of the valuation practice.

Steve Woolgar [SW]: So, CF, how did you feel after that?

C-F Helgesson [CF]: It was disappointing, to have the award and then have it taken away again.

SW: Disappointing?

CF: Well, actually, pretty insulting. Really annoying.

SW: But wait. Did you really believe you had won a Highly Cited Researcher Award?

CF: What?

SW: I mean did you really believe that you had won one?

CF: Well, yes.

SW: Really?

CF: Yes. What are you suggesting? 
SW: No no nothing. It's just that ... Is it not a key principle of science and technology studies (STS) that we maintain scepticism about the phenomenon under study. In this case, academic evaluation?

CF: Well yes but ...

SW: So shouldn't our first reaction be to doubt the authenticity of the award?

CF: But ...

SW: Should we not be trying to adhere to the principles of symmetry and impartiality?

CF: Yes, but it's really difficult to maintain symmetry when it happens to you. I mean, the whole thing was beautifully packaged.

SW: How so?

CF: Well it was all very convincing. An impressively official looking letter from Thomson Reuters, personally signed, the honorary badge. References to the selection process, all the other winners, press releases ...

SW: Ahh. You're saying you yourself got caught up in the valuation spectacle!

CF: Of course!

SW: But I saw that you later posted the honorary badge on your office door?

CF: Yes. Both the badge and its retraction are displayed on my office door [see Figure 5].

SW Why did you that?

CF: I was using irony as a form of resistance.

SW: So the choreography goes on?!

CF: Yes, the door display performs the identities of its readers.

SW: The door display tells that we STS-ers are not so easily taken in by this kind of mistake!

CF: So, Steve how do we conclude this research note?

\section{Conclusion}

Several similarities between the HCR and Oscar mishaps suggest the possibility of recurrent patterns in the choreography of repair. These include the retraction of a prior unequivocal statement, the making of a new (equally) unequivocal statement, the consequential reordering of 


\section{Valuation Studies}

roles, and the identification of the cause of the mistake. All these parts of the choreography further align to attempt to isolate the mishap and try to sustain the integrity of the valuation at hand. The choreography does not settle the case: many different kinds of repair work continue beyond the immediate setting of the Oscar ceremony.

In both cases, the drama of the ceremony entails the enactment of key identities and of the social relations between them (the adjudicating organisation, the announcers, the recipients, the material enactments of the award). These work together to establish the significance and prestige of the award, and thence the importance of celebrating achievement. The recognition of a mistake then engenders a process of repair. (Evident from the Oscar materials, but not from the information available to us from the HCR episode, is a brief period when participants consider 'soldiering on' rather than revealing the mistake at all). The repair process involves, crucially, articulating a distinction between the evaluation machinery and its announcement. This distinction enables casting the announcement as a mere epiphenomenon to the evaluation machinery. This in turn enables accountability for the mistake to be attributed to "human error" in the announcement of the award while the integrity of the evaluation machinery is presented as unaffected. The overall effect is that something went wrong, but everything is fine.

At the same time the whole process of the revelation of the mistake and its subsequent repair can be seen as an attempt to reinforce and preserve what is at stake for the actors involved. In particular we note how in both cases the prospective value of the award, its folding into situations and contexts beyond the immediate announcement, is reasserted by participants. Attempts to sustain the integrity of the evaluation machinery are also attempts to reconfirm the value and significance of the award. Yet the repair is not complete. The event itself leaves traces which are folded into the organisation of future evaluation and award, and into the conduct of individual participants on subsequent occasions.

We see then that not only is the public performance of valuation ritualised, but so too is the repair of mistakes. By focusing in detail on the revelation and repair of mistaken evaluation we can see that the integrity of evaluation is the upshot of a complex social choreography. This involves the enactment of various identities and social relations, including the adjudication process, the adjudicators, "true" and "false" recipients of the award, non-recipients, the audience and so on. Despite the potential for considerable upset and complaint, a successful choreography of repair diminishes the voices of prospective malcontents and solidifies the significance and integrity of the valuation practice.

Our brief examination here of two visible valuation mishaps is suggestive of the merits of further close examination of mistakes in 
evaluation. This entails both the processes of their possible disclosure and the subsequent sequence of events. There is much more to explore in the dynamics of public choreographies of repair. In addition, the theme of mishaps further inspires thinking about and examining instances where a potential valuation mishap is repaired by letting it all slide. What for a brief moment could have become the wrongly awarded prize, the wrong candidate being hired, etc, in fact becomes the right outcome. How do such practices and choreographies of repair look? What are the dynamics that flip it either way, and what more could the examination of such instances tell us about the dynamics of valuation as a social practice?

Acknowledgements: An earlier version presented at 4S Boston 31 August 2017 under the title "Mistakes and Mishaps in Academic Evaluation." We are grateful for comments from this $4 \mathrm{~S}$ meeting, from participants in the Linköping Tema $\mathrm{T}$ ValueS Seminar, from the associate editor Andrea Mennicken, as well as other members of the editorial board.

\section{References}

Cussins, Charis. 1996. "Ontological Choreography: Agency through Objectification in Infertility Clinics." Social Studies of Science 26(3): 575610.

Deleuze, Gilles. 1993. The Fold: Leibnitz and the Baroque. University of Minnesota Press

Muniesa, Fabian, and Claes-Fredrik Helgesson. 2013. "Valuation Studies and the Spectacle of Valuation." Valuation Studies 1(2): 119-123.

Woolgar, Steve. 1980. "Discovery: logic and sequence in a scientific text." In The Social Process of Scientific Investigation, Sociology of the Sciences Yearbook, Vol. 4, edited by Karin Knorr et al., 239-268. Dordrecht: Reidel.

Woolgar, Steve. Forthcoming. "It could be otherwise: Jimmy Savile and the situated dynamics of revelation." 


\section{Valuation Studies}

Claes-Fredrik Helgesson is co-Editor-in-Chief of Valuation Studies and Professor in Technology and Social Change at Linköping University, Sweden. He is co-editor with Isabelle Dussauge and Francis Lee of the volume Value Practices in the Life Sciences and Medicine (Oxford University Press, 2015). Helgesson is currently concluding with Francis Lee the research project "Trials of Value" which explores valuation practices in the context of experimental design in biomedical research.

Steve Woolgar is Professor of Science and Technology Studies at Linköping University, Sweden. His recent books are Mundane Governance (with Dan Neyland, OUP 2013); Globalisation in Practice (with Nigel Thrift and Adam Tickell, OUP, 2014); Representation in Scientific Practice Revisited (with Janet Vertesi, Catelijne Coopmans and Mike Lynch, eds, MIT, 2014) and Visualisation in the Age of Computerisation (with Annamaria Carusi, Aud Sissel Hoel and Tim Webmoor, eds, Routledge, 2014). His current projects include It Could $B e$ Otherwise, an investigation of the limits of provocation and intervention. 